\title{
51 FASTENING ELEMENTS IN \\ CONCRETE STRUCTURES - NUMERICAL SIMULATIONS
}

\author{
J. OŽBOLT and R. ELIGEHAUSEN \\ Institut für Werkstoffe im Bauwesen, Stuttgart University, \\ Germany
}

\begin{abstract}
Anchoring elements such as headed and expansion studs and grouted or undercut anchors, are often used for local transfer of loads into concrete members. In order to better understand the failure mechanism, a large number of experiments have been carried out in the past. However, due to the complicated three-dimensional load transfer a very few or no numerical studies have been performed for a number of different fastening situations i.e. influence of the embedment depth, crack-width influence (fastening in cracked concrete), influence of the edge distance etc. Therefore, in the present study some results of the axisymmetric and three-dimensional numerical analysis of the headed studs embedded in plane concrete block are presented. Influence of different geometrical and material parameters have been studied employing finite element method and nonlocal microplane model. Comparison between experimental and numerical results indicate reasonable good agreement. Generally it has been observed that the failure mechanism is governed by fracture energy rather than by tensile strength of concrete. As a consequence, the size effect is strong and close to linear elastic fracture mechanics.

Keywords: Concrete, Fastening, Finite element analysis, Nonlocal microplane model, Fracture, Size effect.
\end{abstract}

\section{Introduction}

In current engineering practice, headed anchors are used to transfer load into reinforced concrete members. Experience, a large number of experiments and numerical studies confirm that fastenings are capable to introduce the force into the reinforced concrete member without using a reinforcement. As shown by Eligehausen and Sawade (1989) and Eligehausen and Ożbolt (1991), the main reason for this is a stable crack propagation up to peak load, what is a consequence of a three-dimensional stress-strain state in the load transfer zone. However, since no reinforcement is present, the fracture process zone is relatively small and failure is rather brittle i.e. very close to a linear elastic fracture mechanics type of failure. Therefore, it is im- 
portant to clearly understand the failure mechanism and the influence of different geometrical and material parameters on the load capacity. This is of course not simple because in the practice many types of fastenings exist as well as a number of different geometrical situations.

The simplest fastening case is a single headed stud anchor transferring a force into a large concrete block. Provided the steel strength of the stud is high enough, headed studs embedded in a concrete block subjected to tensile loading fail by pulling a concrete cone out of it. The failure is due to the failure of concrete in tension by forming a circumferential crack growing in so-called mixed mode (Eligehausen and Sawade, 1989). In recent years several attempts have been made to understand this growth and to predict the pull-out load of headed studs (Ottosen, 1981; Eligehausen and Sawade, 1985; Krenchel and Shah, 1985; Ballarini, Shah and Keer, 1986). Summarizing this activities it can be said that material models based on plasticity and on macroscopic stress-strain relationships together with stress criteria are not capable to predict behavior of anchors as observed in experiments (Eligehausen and Sawade, 1989). Furthermore, the predicted failure load depends on the finite element size and load step size (Cedolin and Bażant, 1980). A better explanation of anchorage failure mechanism can be expected using more general material models based on fracture mechanics. Generally, the numerical analysis has to be carried out using three-dimensional finite elements together with a realistic threedimensional material model for concrete. Not only material nonlinearity, but also fracture process in concrete must be correctly simulated.

Due to above mentioned complexity, for geometrically complicated types of fastenings, presently only experimental results are available. Based on these test results design rules were developed that are used in the engineering practice. However, recently rather sophisticated nonlocal microplane model for concrete is developed and implemented into a three-dimensional finite element code (Bažant and Ożbolt, 1990; Ożbolt and Bažant, 1992). This model has been successfully used in three-dimensional numerical studies of different problems (Bażant, Ożbolt and Eligehausen; 1992) and therefore it is also employed here.

In the present study axisymmetric finite element analysis of the single fastening element embedded in uncracked concrete block is carried out in order to investigate the influence of macroscopical concrete properties (tensile and compression strength, fracture energy) and the geometry of the structure (embedment depth, size of the headed stud, edge distance) on the concrete cone failure load. Beside this, in order to study the influence of the distance of the anchor from the edge as well as the influence of the crack width on the pull-out failure load, three-dimensional nonlinear analysis is also carried out. Results of the analysis are compared with the experimental ones.

\section{Axisymmetric analysis - material parameters and size effect}

2.1 Headed anchor with embedment depth $h_{v}=130 \mathrm{~mm}$

A single headed anchor embedded in a large uncracked concrete block is analyzed 
using axisymmetric four-node finite elements. The typical finite element mesh is shown in Fig. 1. Pulling of the anchor is performed by prescribing displacements at the bottom of the stud. Contact between steel stud and concrete exists only under the head of the stud. To account for the restraining effect of the embedded anchor, the displacements of the concrete surface along the steel stud in the vicinity of the head are fixed in direction perpendicular to the load direction. The supports are supposed to be fixed in both directions.

Summary of geometrical and material parameters that are used and varied in the analysis are shown in Table 1.

In order to demonstrate that the present numerical approach is able to correctly prescribe failure load the numerical results are first compared with experimental results. Therefore, basic (reference) material parameters and geometry of the specimen used in the analysis are similar as in the experiment (See. Fig. 1 and Table 1 - example 1).

Table 1. Parameters varied in the analysis

\begin{tabular}{|c|c|c|c|c|c|c|c|}
\hline Exam & noos & $\begin{array}{l}\text { tonavion } \\
\text { otrgth it: } \\
\text { (MAPa) }\end{array}$ & $\begin{array}{l}\text { compr stroth } \\
\text { (M) } \\
\text { (MPa) }\end{array}$ & $\begin{array}{c}\text { tract } \\
\text { onergen } \\
G \text {, } \\
\text { oN/mmul }\end{array}$ & $\begin{array}{c}\text { Young modul. } \\
\text { E. } \\
\text { IMPPal }\end{array}$ & $\begin{array}{l}\text { ches } \\
\text { nongeth } \\
6 \\
\text { (nmm) }\end{array}$ & vence. \\
\hline 1 & 35 & 172 & 176 & 0064 & 23500 & 6 & tost \\
\hline $\begin{array}{l}2 \\
3 \\
4 \\
\end{array}$ & 35 & $\begin{array}{l}172 \\
1.70 \\
1.96 \\
\end{array}$ & 176 & $\begin{array}{ll}0 & 064 \\
0 & 117 \\
0 & 165 \\
\end{array}$ & 23500 & 8 & $\begin{array}{l}a_{1} \\
a_{1} \\
a_{1}\end{array}$ \\
\hline $\begin{array}{l}5 \\
6 \\
\end{array}$ & 52 & 172 & $\begin{array}{l}176 \\
207 \\
\end{array}$ & 0064 & 23500 & 6 & 4 \\
\hline ? & $\begin{array}{l}55 \\
52 \\
\end{array}$ & 172 & 178 & 0.064 & 23500 & 6 & $\alpha_{0}$ \\
\hline $\begin{array}{l}9 \\
10 \\
11\end{array}$ & 35 & $\begin{array}{l}1.41 \\
1.70 \\
1.90 \\
\end{array}$ & 17.6 & 0.070 & 23500 & 6 & 5 \\
\hline $\begin{array}{l}12 \\
13 \\
14 \\
\end{array}$ & 35 & 190 & $\begin{array}{l}178 \\
251 \\
325 \\
\end{array}$ & 0070 & $\begin{array}{l}23500 \\
33500 \\
43500\end{array}$ & 6 & $\begin{array}{l}\text { E. } \\
E_{0} \\
\text { E. }\end{array}$ \\
\hline $\begin{array}{l}15 \\
18 \\
17\end{array}$ & 35 & 1.80 & 251 & & 33500 & $\begin{array}{c}6 \\
12 \\
24\end{array}$ & i \\
\hline
\end{tabular}

After showing that the used approach is effective, the influence of the major macroscopical concrete properties has been investigated i.e. compression and tension strength, concrete fracture energy and size of the head are considered as parameters. Influence of the characteristic length of the nonlocal continuum $\left(l_{c}\right)$ is also studied. In all examples the embedment depth $\left(h_{v}=130 \mathrm{~mm}\right)$ and the diameter of the steel bar $(\phi=22 \mathrm{~mm})$ are keept constant. The finite element mesh for the larger headed stud case $\left(d_{h}=52 \mathrm{~mm}\right)$ is slightly modified. Basic value of the concrete Young's modulus $\left(E_{\mathrm{c}}=23500 \mathrm{MPa}\right)$ and Poisson's ratio $(\nu=0.18)$ are taken the same as in the above mentioned experiment. Used fracture energy values $\left(G_{F}\right)$ were calculated employing a unit area finite element with length $\mathrm{l}=360 \mathrm{~mm}$ (similar as in experiment). To demonstrate the influence of the initial Young's modulus of elasticity and of the characteristic length, parametric studies with three different initial Young's modulus of elasticity i.e. three different characteristic length of nonlocal continuum, keeping all other parameters constant, are also carried out. 
2.2 Headed anchor with variable embedment depth

In order to investigate size effect in fastening of headed stud in concrete block, the finite element analysis as proposed by RILEM TC 90-FMA have been carried out. The specimen shape and the typical finite element mesh are shown in Fig. 2. The size effect is analyzed using three geometrically similar specimens with the size increase by a factor of three. The geometry of the specimens is related to the embedment depth $h_{v}$. Three embedment depths are considered: $h_{v}=50,150$ and $450 \mathrm{~mm}$. The distance between support and anchor is $2 h_{v}$, so that the unrestricted formation of the failure cone is possible. In all cases analyzed pulling out of the anchor is performed by prescribing displacement at the bottom of the stud. Material parameters are taken as follows: uniaxial tensile and compression strength $f_{t}=3 \mathrm{MPa}$ and $f_{c}=$ $40 \mathrm{MPa}$, concrete fracture energy $G_{F}=0.1 \mathrm{~N} / \mathrm{mm}$ (assuming a tension specimen length of $360 \mathrm{~mm}$ ), Initial Young's $E_{\mathrm{c}}=30000 \mathrm{MPa}$ and Poisson's ratio $\nu=0.20$. Characteristic length of the nonlocal continuum is taken $l_{c}=12 \mathrm{~mm}$.

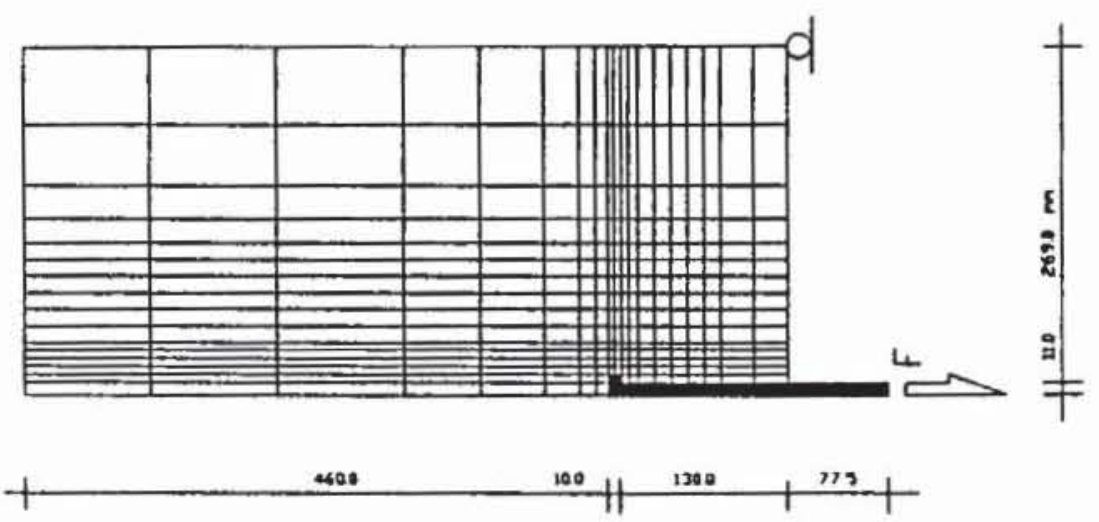

Fig. 1 Geometry and FEM used in parameter study
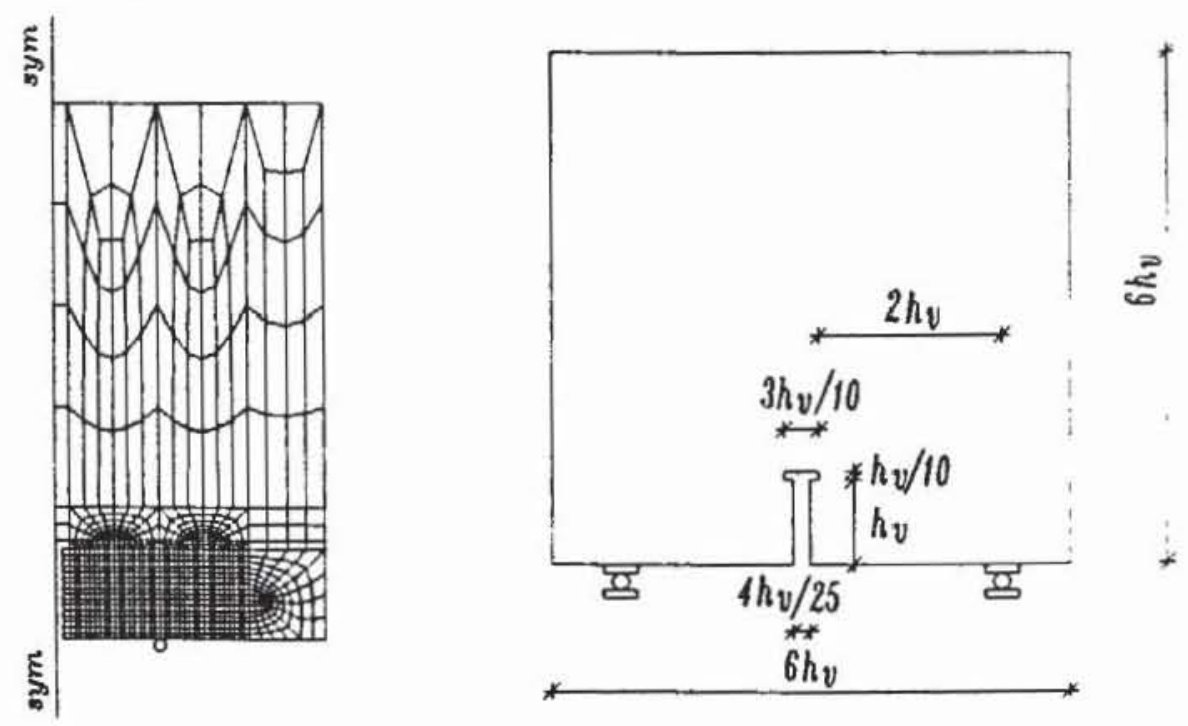

Fig. 2 Geometry and FEM used in the size-effect study 


\subsection{Results of the axisymmetric analysis}

\subsubsection{Comparison of Numerical and Test Results for Headed Anchor with $h_{v}=130 \mathrm{~mm}$}

In Fig. 3, the numerically obtained load-displacement curve is compared with the measured one. As can be seen, the calculated and measured failure load agree rather well. This could be expected, because the characteristic length was fixed according to this experiment $\left(l_{c}=6 \mathrm{~mm}\right)$.

While the calculated initial stiffness agrees well with the measured value, the displacements at failure are smaller than observed in the experiment. It should be noted that the area of the anchor head is relatively small $\left(d_{h}=35 \mathrm{~mm}\right)$, and due to this the average compression stress under the head at failure load is about 10 times larger than the uniaxial concrete compression strength $f_{c}$ (the maximum calculated value in one integration point is $20 f_{c}$ ). Therefore, most of the displacements in the load displacement diagram (see Fig. 3) is due to concrete compression softening under the anchor head. The concrete pre- and post-peak behavior under very high compression in 3D stress-strain state have to be correctly modeled to predict load-displacement curve. As can be seen from Fig. 3, assumed peak stress in the analysis is too high in comparison to the behavior found in the test i.e. calculated displacement are too small. According to Eligehausen and Sawade (1989), most of the total displacement is due to concrete compaction under the anchor head. However, in general the calculated displacement field is in good agreement with the experimental observations.

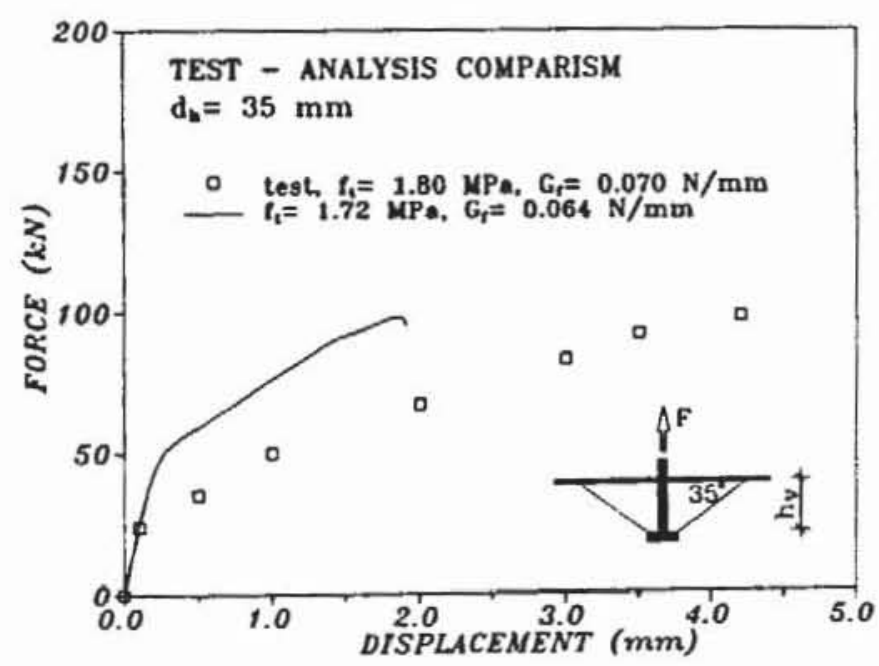

Fig. 3 Test - analysis load displacement curves

It is observed that the circumferential cracking starts relatively early at the anchor head and progresses in a stable manner towards the concrete surface, radial cracks are initiated at much higher loads at the surface. Failure is caused by circumferential cracking. The calculated slope of the failure cone surface is in good agreement with the experimentally measured results (Eligehausen and Sawade, 
1989). The average angle between the pulled cone surface and the concrete surface amounts to $\alpha=35^{\circ}$.

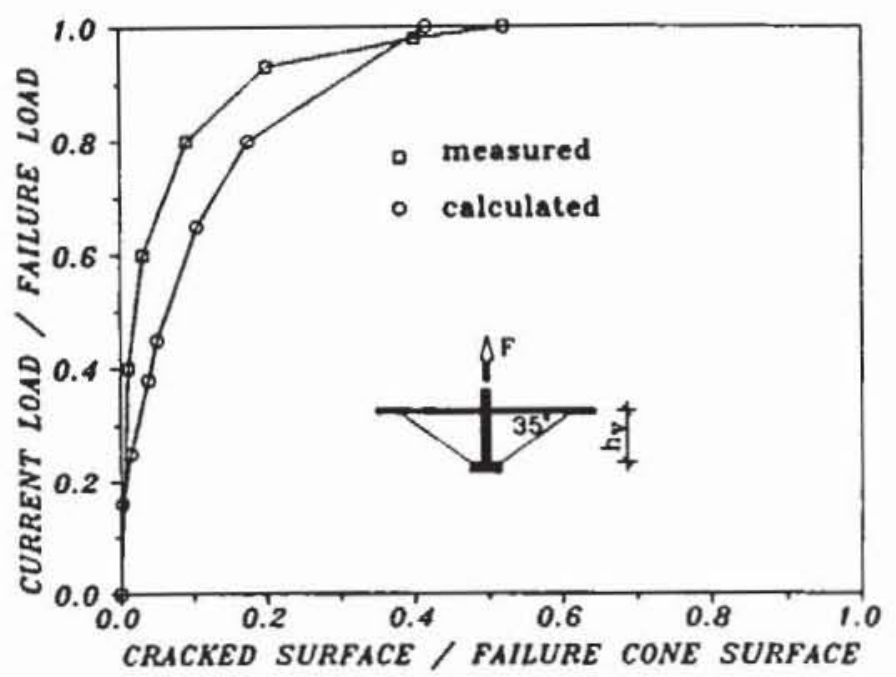

Fig. 4 Calculated and measured crack surface area

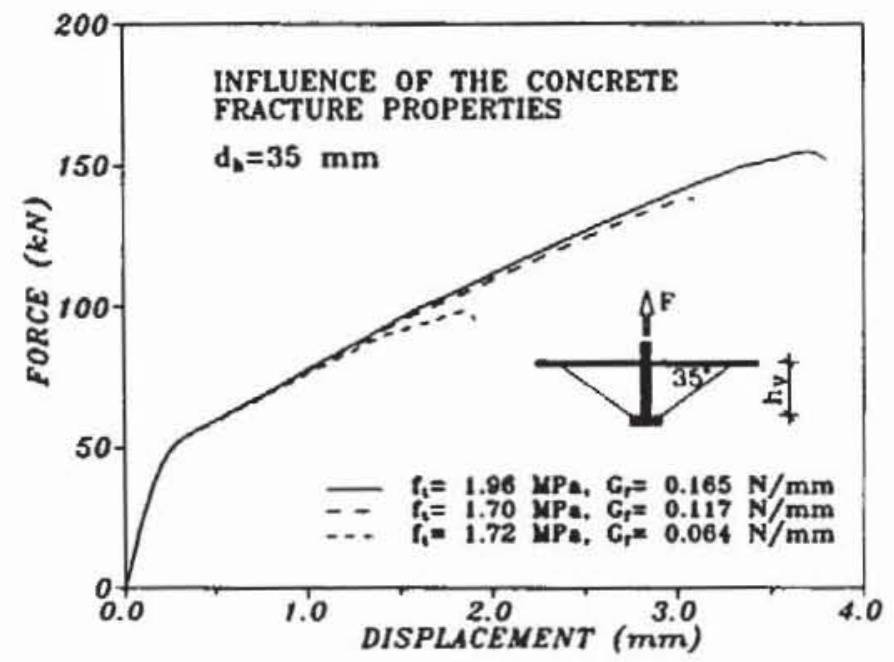

Fig. 5 Load-displacement curves for different $G_{F}$ values

In Fig. 4, the ratio between the crack cone surface area and the total crack cone surface area (calculated for $\alpha=35^{\circ}$ ) is plotted. Stable crack growth starts at about $30 \%$ of the failure load and further crack growth is very stable up to the peak load, when unstable crack development starts. These results are again in good agreement with experimental observations based on measurements of concrete strains (Eligehausen and Sawade, 1989).

Summarizing, the obtained results are in good agreement with experimental findings. This is valid for the fracture process, displacement field and failure load.

2.3.2 Influence of the material parameters on the anchor behavior In Fig. 5 the influence of the fracture energy $\left(G_{F}\right)$ on the load displacement behavior 
is shown. Three different $G_{F}$ values are considered (see Tab. 1). The concrete compression strength $\left(f_{c}=17.6 \mathrm{MPa}\right)$ is fixed, and average tension strength used was $f_{t}=1.79 \mathrm{MPa}$. Fig. 5 clearly indicates a strong dependency between fracture properties of concrete and failure load. Roughly, the failure load is proportional to the square root of the fracture energy (Fig. 6). This finding is confirmed by analytical and experimental results obtained by Sawade (1992).

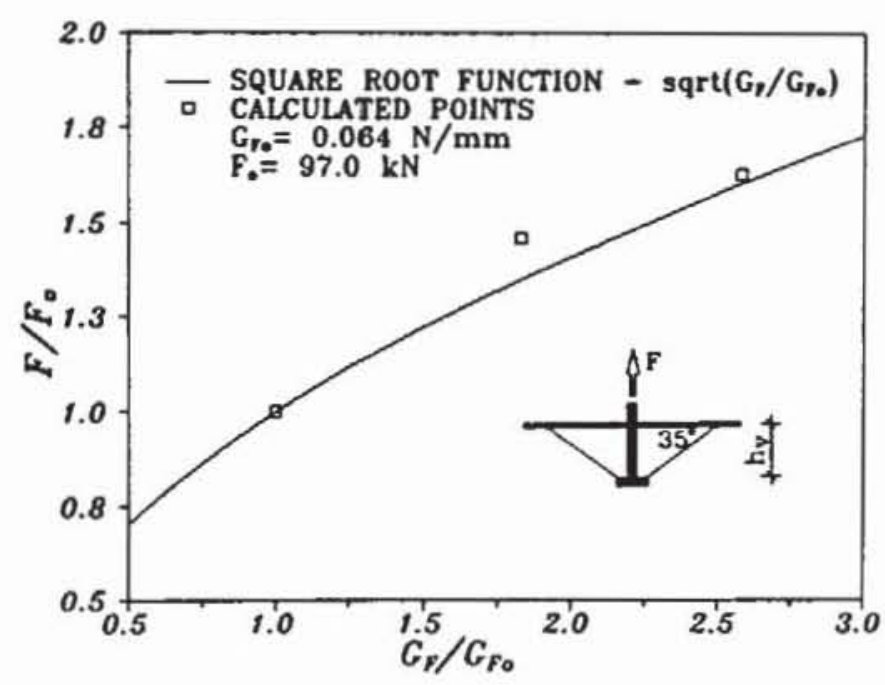

Fig. 6 Relation between failure load and $G_{F}$

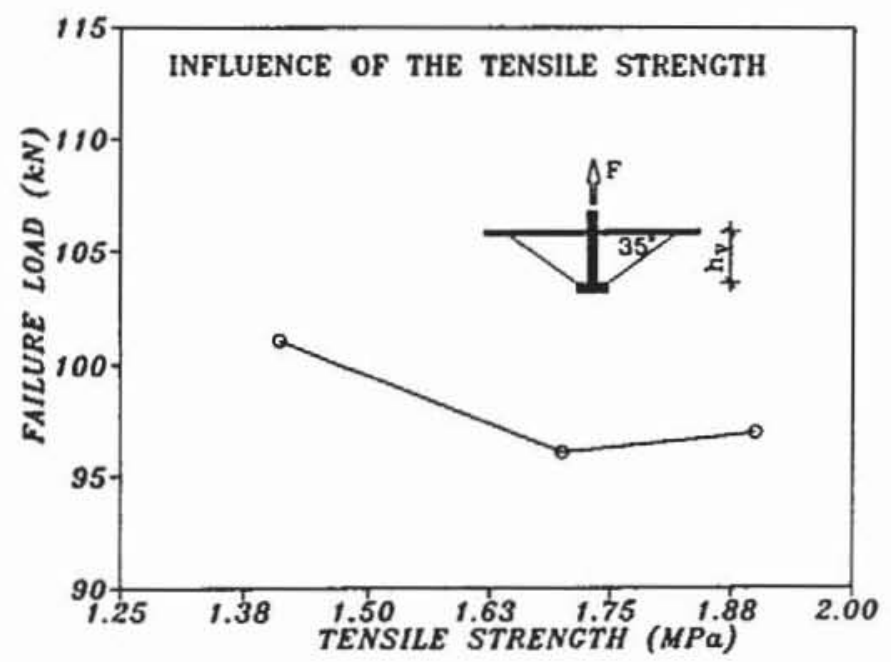

Fig. 7 Tension strength influence on the failure load

In Fig. 7 the influence of the tension strength on the failure load is shown. Namely, concrete with three different values of tension strength (see Tab. 1) and approximately constant fracture energy is analyzed. Concrete compression strength and head diameter were constant. The results indicate no significant influence of the tension strength on the failure load. According to this, the fracture energy seems to be the governing parameter in the analysis of headed anchors.

The influence of the concrete compression strength is demonstrated in Fig. 8, 
where load-displacement curves for two specimens with head diameter $d_{h}=52 \mathrm{~mm}$ are plotted. Tension strength and the fracture properties of the concrete are constant, while two different concrete compression strengths are considered (see Tab. 1). Results clearly indicate insensitivity of the failure load on the concrete compression strength, but the displacement at failure is smaller if the concrete compression strength is higher.

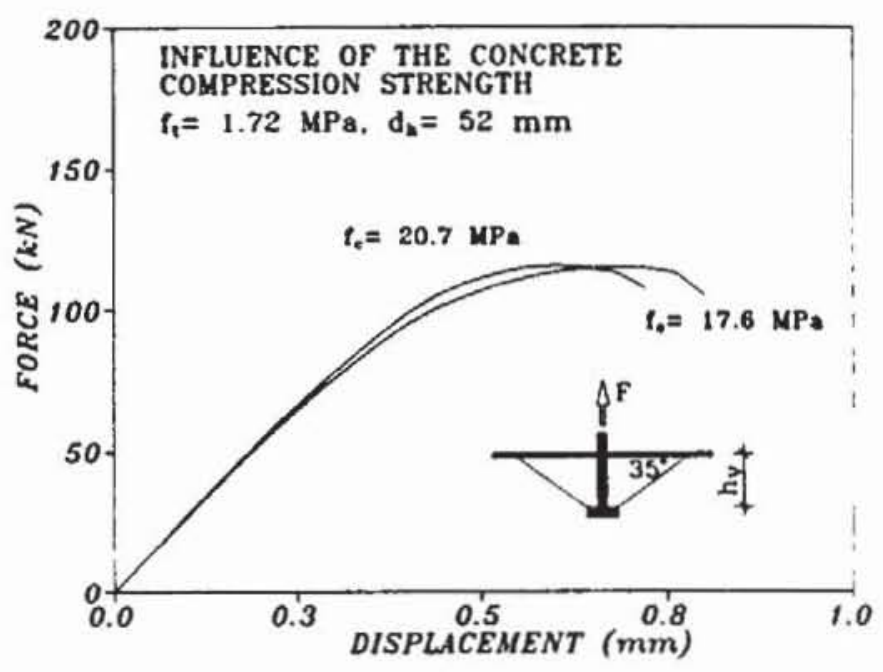

Fig. 8 Compression strength influence on the failure load

In Fig. 9 the load-displacement curves of two specimens with the same concrete properties but different head diameters $\left(d_{h}=35\right.$ and $\left.52 \mathrm{~mm}\right)$ are compared. It can be seen that, within the range of the assumed head diameters, the failure load does not depend significantly on the head diameter, that means of the concrete compression stress-strain state under the head. When increasing the effective head area by a factor of 3 , the increase of the calculated failure load is only $17 \%$. For a head diameter $d_{h}=52 \mathrm{~mm}$ the average compression stress under the load at failure is only about $3.75 f_{c}$ compared to $10 f_{c}$ for $d_{h}=35 \mathrm{~mm}$. Due to this reduction of the compression stress the displacement of the anchor head is much smaller. Therefore, with decreasing head diameter concrete compression softening under the head contributes larger displacement at failure load. This numerical results are in agreement with test evidence (Elfgren et. all., 1988; Furche, 1988). For anchor head $d_{h} \ll 35 \mathrm{~mm}$, the displacement of the anchor head will increase even more, reducing the actual embedment depth and thus the concrete cone failure load (Furche, 1988).

From the numerical point of view, analysis of the specimen with smaller head size, converges very slowly and requires considerably more computer time than analysis of specimen with larger head size. This is a consequence of compression softening in 3D stress-strain state under the anchor head.

In Fig. 10 the influence of the initial modulus of elasticity on the failure load is shown. Geometry and all concrete material parameters were fixed (see Tab. 1). According to the numerical results, the increase of the failure load is proportional to the $E_{0}^{2 / 3}$. This increase is slightly larger than is obtained by Sawade (1992), using 
linear elastic fracture mechanics (LEFM), where the increase was found to be to the power of $1 / 2$. The differences are probably due to the fact that the numerical analysis is based on the nonlinear fracture mechanics approach. Namely, in contrast to LEFM where the modulus of elasticity is kept constant up to reaching the concrete tensile strength, in the present analysis this modulus is continuously changing from $E=E_{c}$ (at origin) to $\mathrm{E}=0$ at the peak stress.

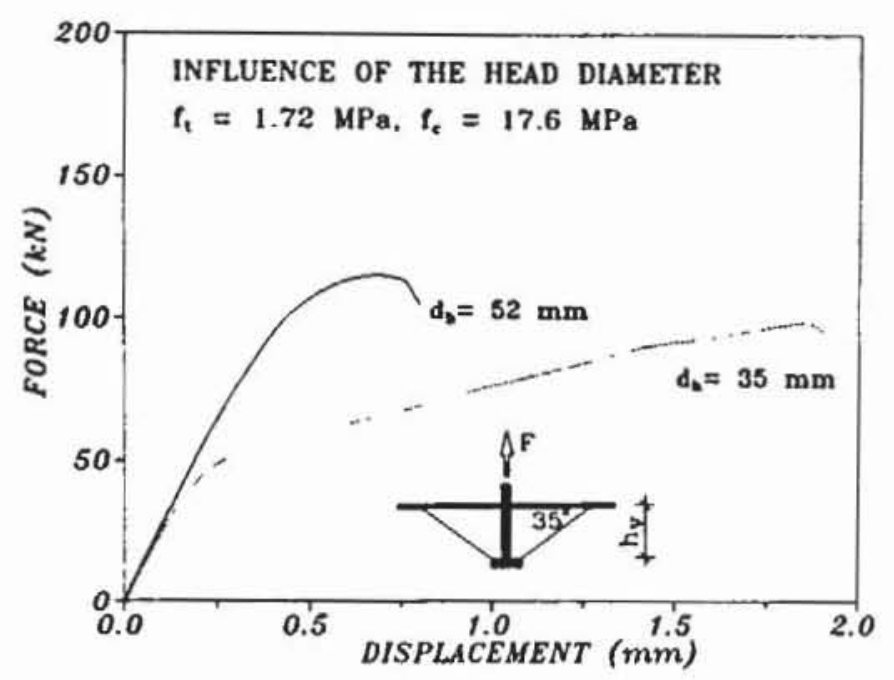

Fig. 9 Influence of the head stud size on the load-displacement curve

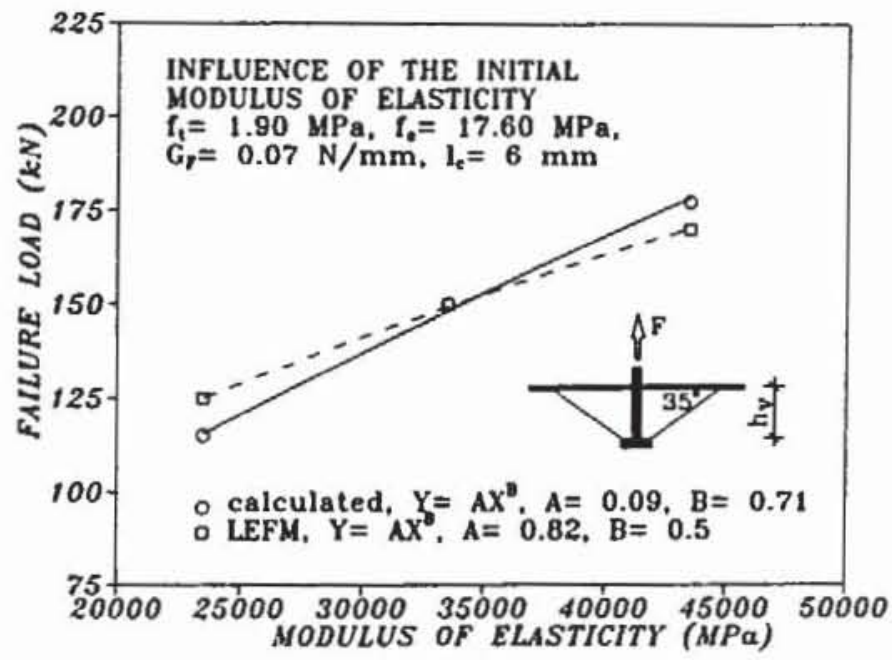

Fig. 10 Influence of the Young's modulus on the failure load

Finally, to demonstrate that the characteristic length of the nonlocal continuum $\left(l_{c}\right)$ has a considerable influence on the failure load, a parameter study is performed (see Tab. 1) in which the concrete properties and geometry were kept constant and only $l_{c}$ is varied. The results of the analysis, shown in Fig. 11, exhibit significant influence of the characteristic length on the concrete cone failure load in the analysis of the headed anchors. This increase of the failure load is approx. proportional to $l_{c}^{1 / 3}$. Consequently, the question arises: how this characteristic length can be cor- 
rectly determined and what is the relation between the fracture concrete properties and $l_{c}$ ?. According to the proposal by Bażant and Pijaudier-Cabot (1989), which is based on the smeared crack approach, $l_{c}$ can be correlated with the maximum aggregate size. However, numerical analysis indicate that $l_{c}$ is not a material parameter but depend also on stress-strain state (Bažant, Ožbolt and Eligehausen, 1992). Therefore, recently new nonlocal concept has been proposed (Bažant, 1992) which is based on the crack interactions. In this new approach the characteristic length defines crack-interaction volume that is not constant but also depend on the stress-strain state in the material. Further work is required in order to verify this new approach.

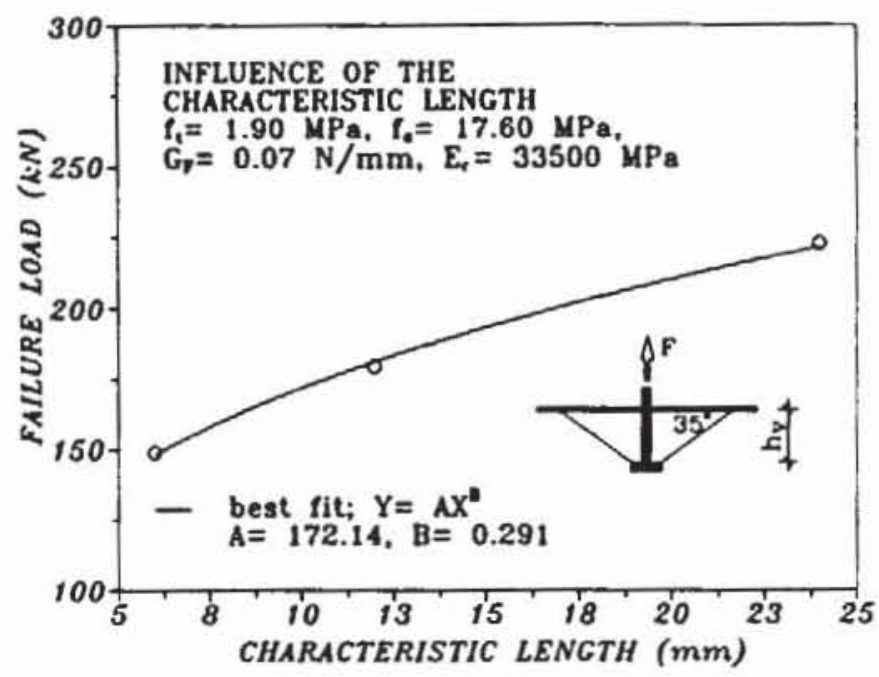

Fig. 11 Influence of the characteristic length on the failure load

Summarizing, the failure of the analyzed headed stud embedded in concrete is due to circumferential cracking of concrete in tension. The compression behavior of concrete under the head is mainly responsible for the displacement at failure. The concrete fracture energy plays a dominant role.

2.3.3 Influence of the Embedment Depth on the Failure Load - Size Effect Load displacement curves for three different embedment depths are shown in Fig. 12. The displacement is monitored under the head. It can be seen that the displacement at peak load increase with increasing embedment depth. Assuming no size effect, the peak load should increase in proportion to $h_{v}^{2}$, that means by a factor of 9 when tripling the embedment depth. The results of the analysis show that the increase in failure load is much less (approximately by a factor 5.7 ) which is a consequence of the size effect. Using the size effect law (Bažant, 1984), the concrete cone failure load can be calculated as:

$$
F_{N}=F_{U} B\left(1+h_{v} / d_{0}\right)^{-1 / 2}
$$

where $F_{N}$ represents load at failure including size effect, $F_{U}$ the would be failure load without size effect, $h_{v}$ the embedment depth while B and $d_{0}$ represents constants 
which are calculated from the linear regression analysis of the obtained failure loads. No size effect ultimate load $F_{U}$ is calculated using the formula:

$$
F_{U}=a\left(\sqrt{f_{c}}\right) h_{v}^{2}
$$

where $f_{c}$ represents the concrete compression strength and $a$ is factor to calibrate calculated failure loads with the measured values and to assure dimensional correctness of Eq. (2). Eq. (2) is proposed by ACI 349, appendix B for the prediction of the concrete cone failure load.

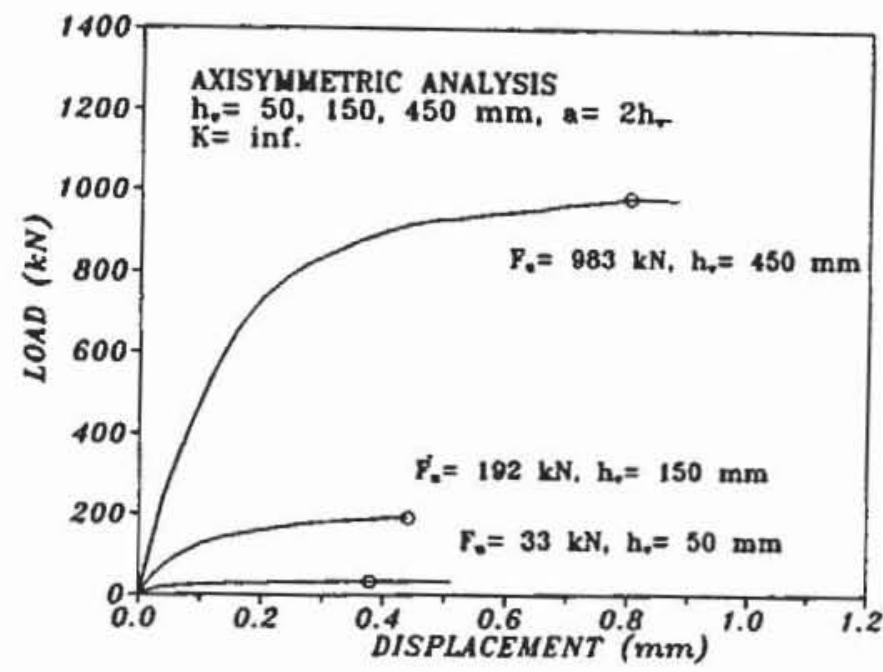

Fig. 12 Load-displacement curves for three different embedment depths

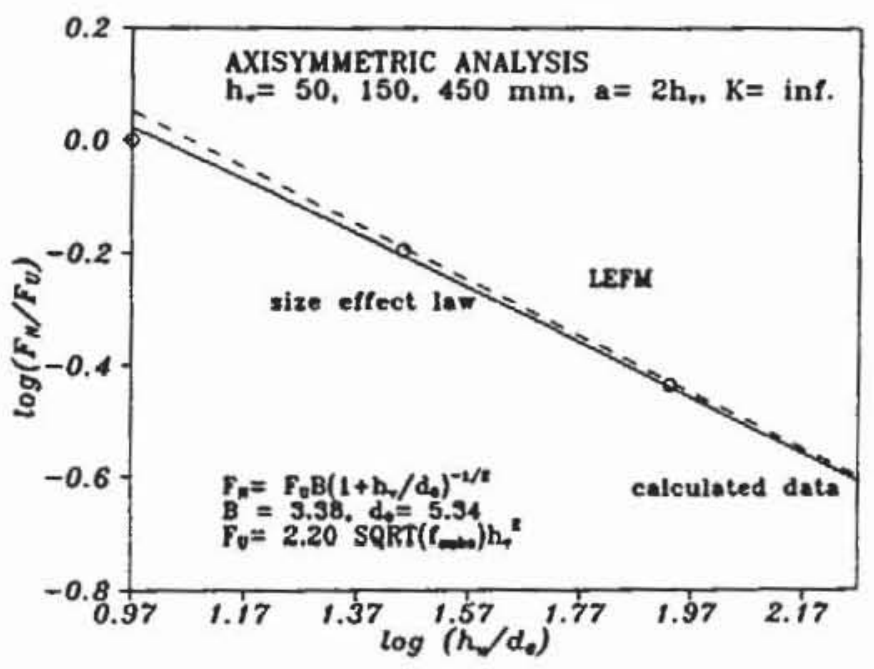

Fig. 13 Size-effect observed in the analysis

In Fig. 13 the results of the analysis are plotted and compared with the size effect law (Eq. (1)). The coefficient $a$ in Eq. (2) is fixed such that the numerically obtained failure load for anchors with an embedment depth $h_{v}=50 \mathrm{~mm}$ is predicted correctly. As can be seen from Fig. 13, the concrete cone failure load exhibit a strong size effect, since the numerical results are close to the linear elastic fracture mechanic 
(LEFM) solution.

In Fig. 14 the results of the analysis are compared with the different failure equations. The relative failure loads as a function of the embedment depth are shown. The failure load for an embedment depth $h_{v}=150 \mathrm{~mm}$ is taken as reference value. Plotted are the relative failure load according to the size effect law (Eq. (1)), a formula that neglects the size effect (Eq. (2)) and a formula derived on the basis of linear elastic fracture mechanics (Eq. (3)) (Eligehausen and Sawade, 1989):

$$
F_{N}=a_{1}\left(\sqrt{E G_{F}}\right) h_{v}^{3 / 2}
$$

In Eq. (3), $a_{1}$ is a constant. The failure loads predicted by Eq. (3) agree rather well with the test results (Eligehausen and Sawade, 1989). Assuming no size effect, the failure loads should increase in proportion to $h_{v}^{2}$, that means by a factor of nine when tripling the embedment depth. The results of the analysis show that the increase of the failure load is much less (approximately by a factor of 5.7). Therefore the size effect should be taken into account in the design of anchorages, otherwise the failure loads are underestimated for small embedment depths and are overestimated for large embedment depths (Fig. 14). The agreement between the size effect formula and the formula based on the linear fracture mechanics is good in the entire embedment range. The size effect has also been observed in tests by Bode and Hanenkamp (1985) and by Eligehausen et al. (1989), (1992). According to these authors, the failure load increases in proportion to $h_{v}^{1.5}$.

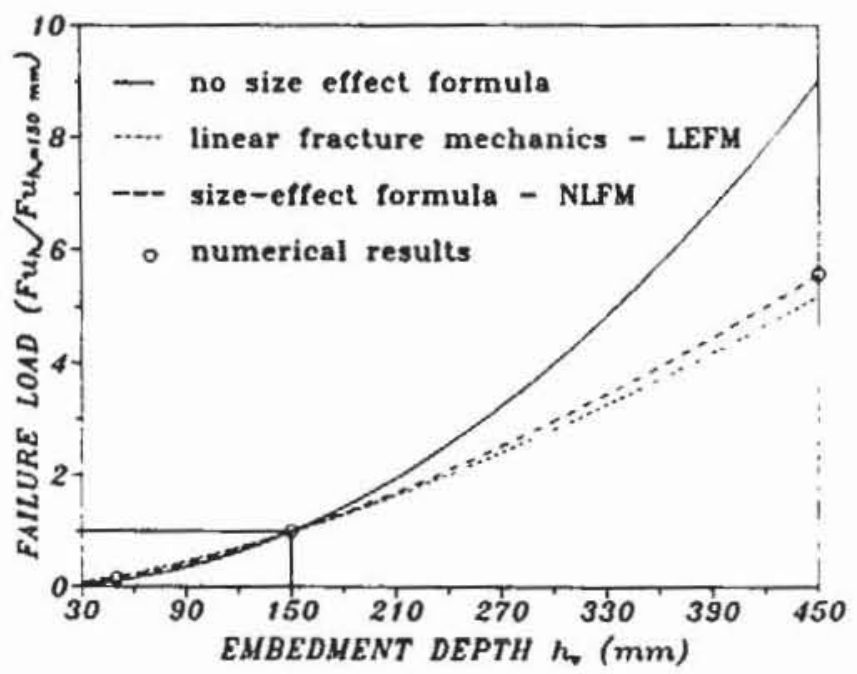

Fig. 14 Different failure equations

The relative shapes of the failure cone for three different embedment depths at peak load, estimated from the numerical analysis, are plotted in Fig. 15. In Fig. 16 the distribution of the tensile stresses perpendicular to the failure cone surface are shown as a function of the ratio $l_{h} / l_{h_{\max }}$ where $l_{h}$ represents the distance from the anchor and $l_{h_{\max }}$ is the failure cone radius taken from Fig. 15. These distributions are estimated from the results of the numerical analysis. From Fig. 15 and 16 the size effect can be explained as follows: With increasing embedment depth the ratio 
diameter of the failure cone to embedment depth decreases, that means the effective relative cone surface area decreases as well. Furthermore, the average stress over the failure surface decreases with increasing embedment depth because the stress distribution is more triangular like, in the case of a large embedment depth, and more parabola like in the case of smaller embedments.

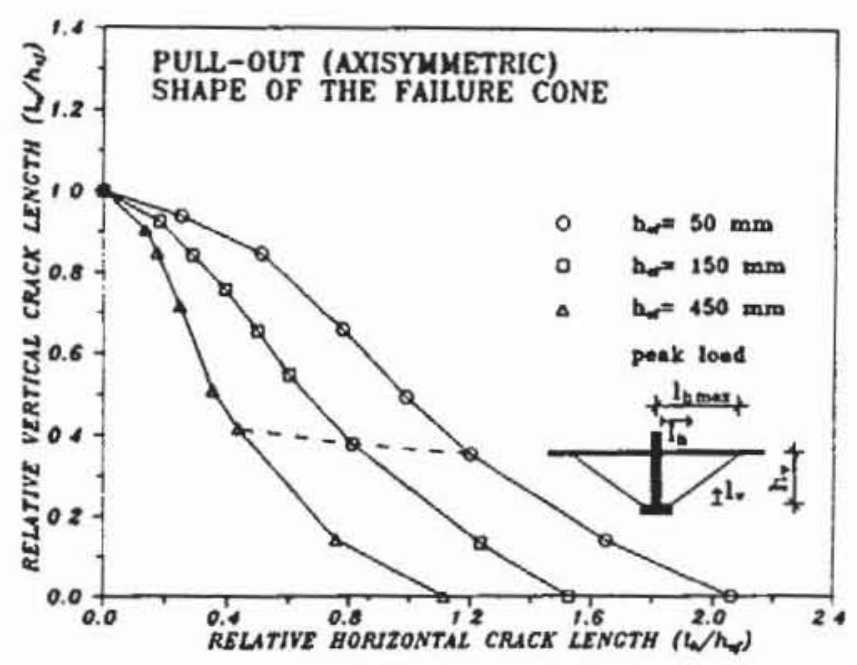

Fig. 15 Shapes of the failure cone surface area

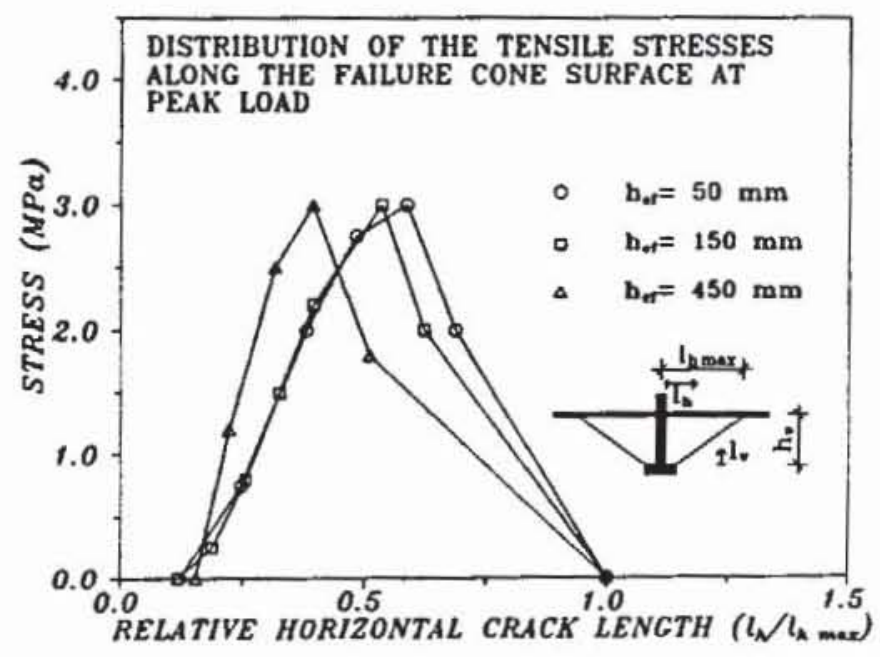

Fig. 16 Tensile stress distribution along the cone surface at peak load

Summarizing, the analysis indicate significant size effect that should be taken into account in design practice (Eligehausen and Ożbolt, 1990; Bažant, Ożbolt and Eligehausen, 1992). 
3 Three-dimensional analysis - the edge and crack width influence

\subsection{Influence of the edge distance on the failure Load}

To investigate influence of the distance between the headed stud and the free edge on the pull-out failure load, nonlinear finite element analysis is performed on the concrete cube specimen (Fig. 17) (Ožbolt, 1991). In the analysis specimen edges are free except the bottom three edges which are fixed in vertical direction. However, the bottom edge of the specimen at the side where the stud is placed is taken as a free. Fixing embedment depth as $h_{v}=90 \mathrm{~mm}$, the distance of the stud from the free edge, $a_{r}$, is varied as $a_{r}=40,80,120,160$ and $200 \mathrm{~mm}$,

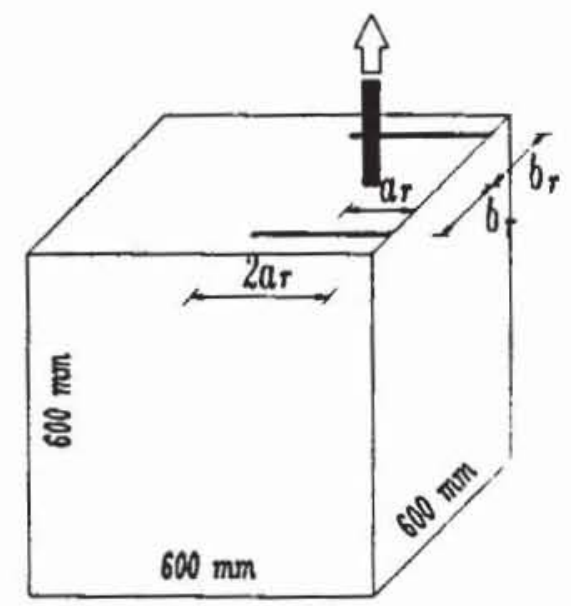

Fig. 17 Edge influence - geometry of the specimen

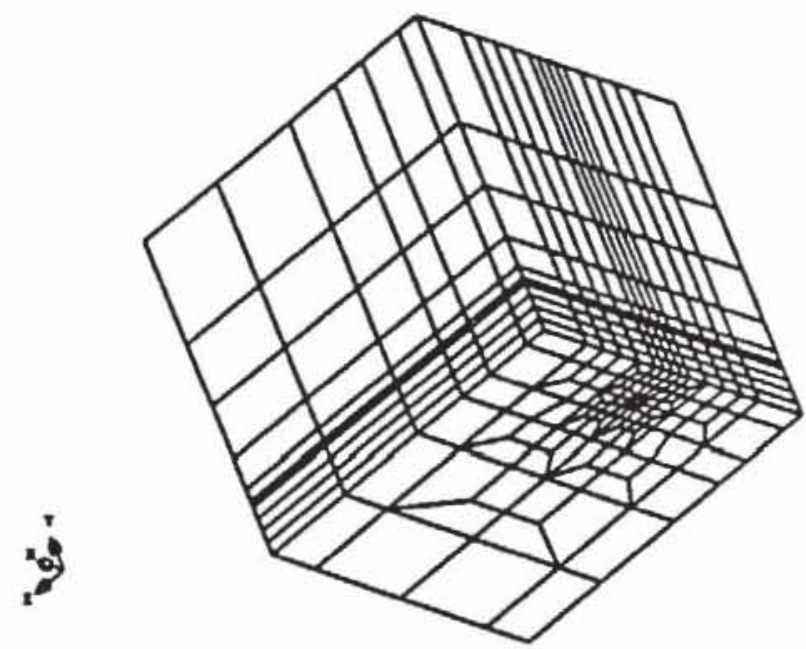

Fig. 18 Edge influence - finite element mesh

In the finite element analysis three-dimensional finite elements with eight nodes and eight integration points are used. A typical finite element mesh is shown in Fig. 18. The spatial discretization is made such that the mesh is relatively fine in the 
fracture process zone and coarse elsewhere.

Analysis is performed assuming basic material properties, Young modulus and Poisson's ratio as: $E_{c}=30000 \mathrm{MPa}$ and $\nu=0.18$. Microplane model parameters are set such that the calculated uniaxial concrete compression strength yields to $f_{c}=34$ $\mathrm{MPa}$ and the uniaxial concrete tensile strength $f_{t} \cong 1.8 \mathrm{MPa}$.

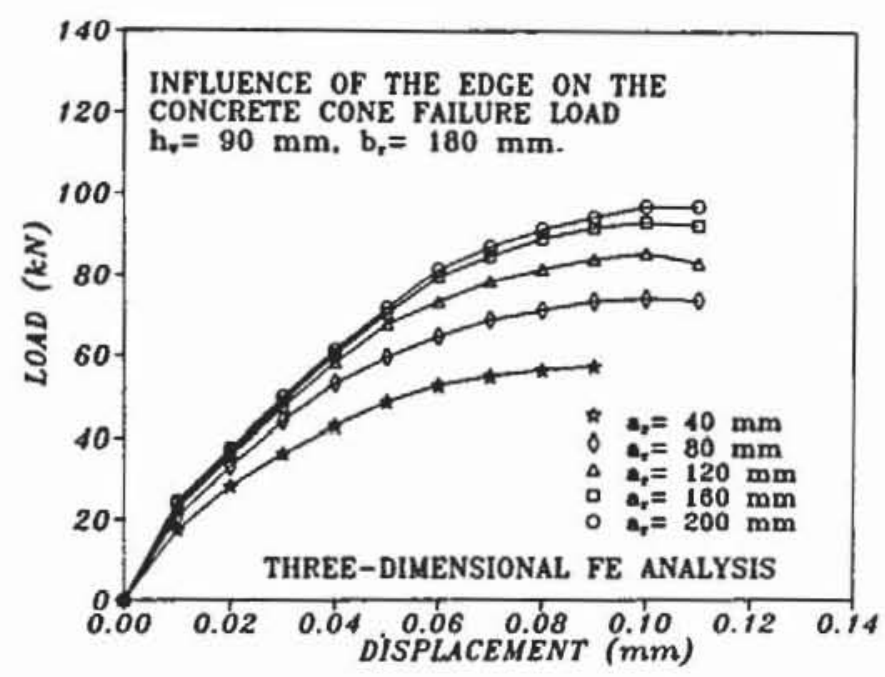

Fig. 19 Load-displacement curves for different edge distances

In order to correctly represent the concrete fracture energy $\left(G_{F}\right)$, it is necessary to properly set the characteristic length of the nonlocal continuum $\left(l_{c}\right)$. However, since no explicit relation between $G_{F}$ and $l_{c}$ exists, the characteristic length is here chosen by fitting the concrete cone failure load for the case $a_{r}=200 \mathrm{~mm}$ (no influence of the edge) using empirical formula (Eligehausen et al., 1988).

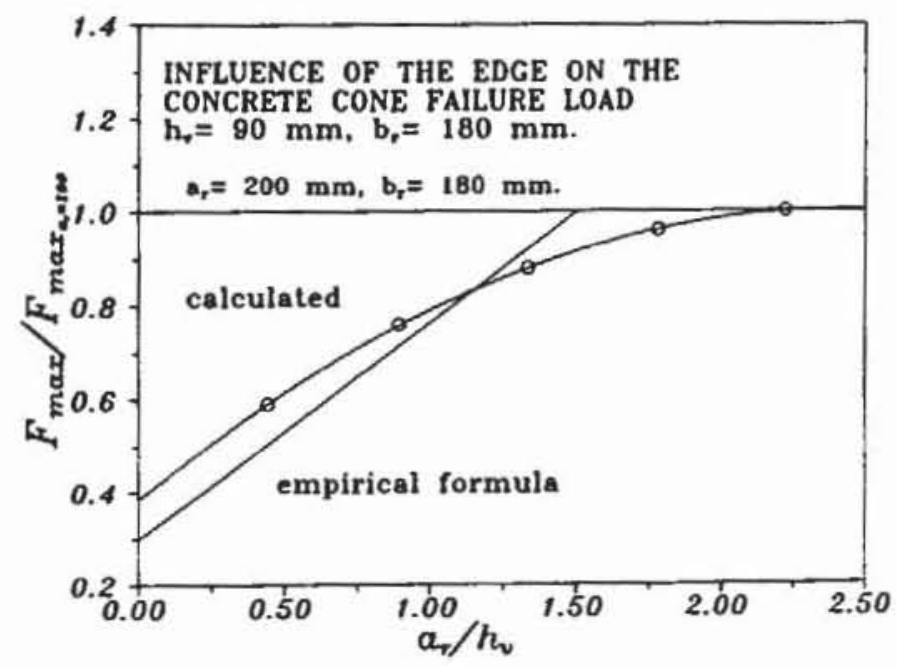

Fig. 20 Relation between failure load and edge distance

Fig. 19 shows calculated load-displacement curves for different $a_{r}$ values. These curves exhibit an increase of the peak load with increasing distance of the stud from the free edge. Displacement at the peak load, for all $a_{r}$ values, is approximately 
constant and does not change significantly by increasing the $a_{r}$ value. Initial stiffness of the stud is practically constant and independent of $a_{r}$.

In Fig. 20 calculated relative values of the peak loads for different values of $a_{r}$ and the best fit curve are plotted as a function of the distance of the stud from the free edge. Results clearly indicate an increase of the calculated failure load with the increase of $a_{r}$ up to approximately $a_{r}=2 h_{v}$. Further increase of $a_{r}$, however, does not significantly increase the peak load. For comparison in the same figure empirical relation between $a_{r}$ and relative peak load is also plotted (Rehm, Eligehausen and Mallée, 1988). As can be seen from Fig. 20, comparison between results of the numerical analysis and prediction formula based on the test results show rather good agreement.

\subsection{Influence of the crack width on the failure load}

The influence of the crack width on the concrete cone pull-out is studied (the same as in the experiments) on the reinforced concrete thick plate dimensions $1000 \mathrm{x}$ $1040 \times 300 \mathrm{~mm}$ (Fig. 21) (Oźbolt, 1991). In the center of the specimen single anchor is embedded with embedment depth $h_{v}=120 \mathrm{~mm}$. In order to initiate crack propagation in the anchor plane, a notch of a length $100 \mathrm{~mm}$ is introduced on the both vertical sides of the specimen (see Fig. 21). The crack width in the specimen is controlled through 12 reinforcing bars. The specimen is vertically supported around the bottom edges as well as around the anchor at the distance $2 h_{v}$.
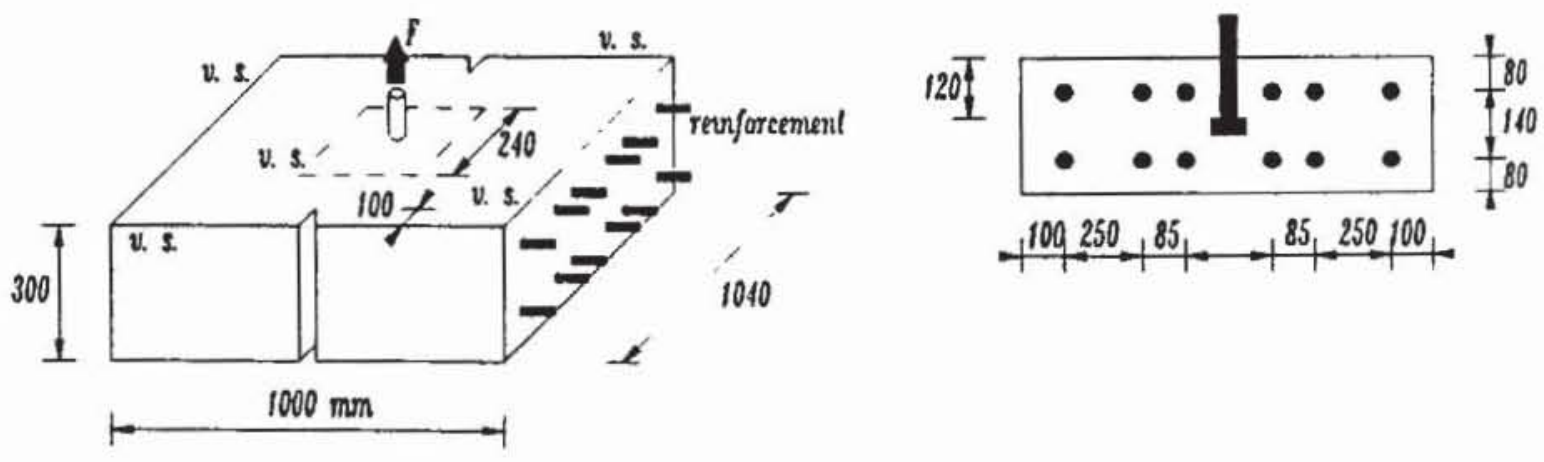

Fig. 21 Influence of the crack width - geometry of the specimen

The loading procedure used in the analysis is the same as it is common in the experiments. First, tensile stresses are introduced through the reinforcement bars (controlling displacement) producing the cracks of a certain width. In the next step the reinforcement extension is keept fixed and pulling out of the anchor is performed (controlling force). This is repeated for different tension stresses in the reinforcing bars i.e. for different crack widths.

In the finite element analysis only $1 / 4$ of the specimen is modeled i.e. symmetry 
is used. The material properties as well as the finite element type used are the same as in previous example. The finite element mesh is shown in Fig. 22.

Since the analysis is based on smeared crack approach the crack width that is introduced through the reinforcement can not be obtained explicitly from the analysis. Therefore, empirical formula is used in order to calculate the crack width from the known reinforcement strains (Rehm and Martin, 1968).

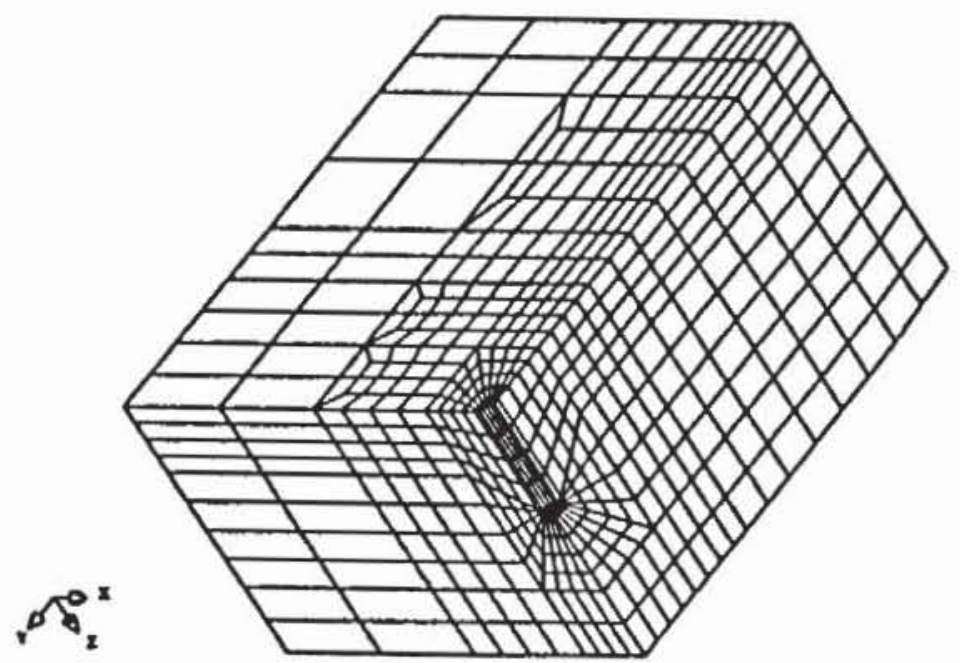

Fig. 22 Influence of the crack width - finite element mesh

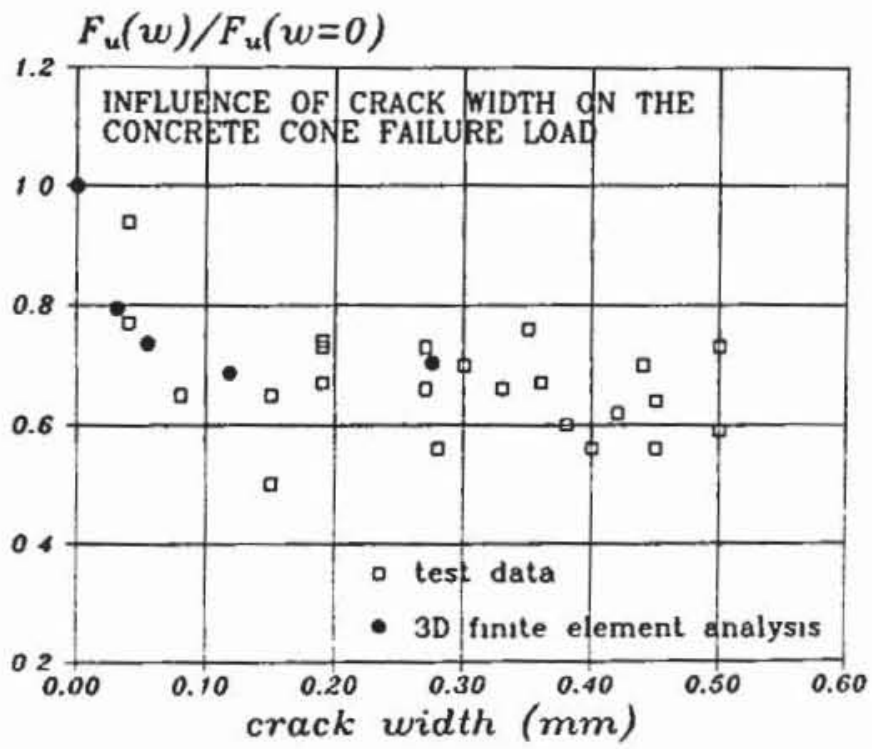

Fig. 23 Influence of the crack width on the failure load (test, calculations)

The relation between the crack width and the failure load, measured relative to the uncracked concrete cone failure load, is shown and compared with test results (Rehm, Eligehausen and Mallee, 1988) in Fig. 23. It can be seen that the failure load decreasing with the increase of the crack width rather steep up to the crack width $\Delta w=0.2 \mathrm{~mm}$. For further increase of the crack width the failure load is constant and reaching approximately $70 \%$ of the failure load obtained for the uncracked concrete specimen $(\Delta w=0)$. Calculated relations between failure load and crack 
width are in good agreement with experimental results (see Fig. 23).

More detailed description of the failure mechanism at different crack widths is given by Ożbolt (1991).

\section{Conclusions}

1. Comparison between axisymmetrical finite element analysis of the single anchor that is embedded in a plane concrete block and test results indicate good agreement. In all analyzed examples failure is due to failure of concrete in tension (circumferential cracking) rather than in compression. Circumferential crack growth starts at about $30 \%$ of failure load and it is very stable up to the peak load. After the peak, unstable crack develops and the final failure cone is formed.

2. The fracture load is mainly influenced by the concrete fracture energy $G_{F}$ and is approximately a square root function of $G_{F}$. The size of the anchor head as well as the concrete compression properties have a rather small influence on the failure load, however they influence the load-displacement relationship significantly. The influence of the concrete tension strength, assuming constant $G_{F}$ value, has small influence on the failure load. On the other side, initial Young's modulus and the characteristic length of the nonlocal continuum significantly influence the failure load.

3. The numerical study of the embedment depth influence on the failure load indicate a significant size effect that is close to linear elastic fracture mechanics. The failure loads increases approximately in proportion to $h_{v}^{\mathbf{1 . 5}}$. This is in good agreement with experimental evidence. Prediction formulas which do not take into account the size effect overestimate the failure load for larger embedment depths. The size effect is due to the fact that the elastic energy at peak load is released from the entire structure and as a consequence, the effective relative failure load surface as well as the area under the tensile stress distribution decrease with increasing embedment depth. The size effect should be take into account in design practice.

4. Results of the $3 \mathrm{D}$ finite element analysis indicate decrease of the failure load if the edge distance is decreasing. This influence practically disappear when $a_{r}$ is greater than $2 h_{v}$. Experiments confirm that calculated results shown in the present analysis are reliable.

5. Three-dimensional finite element study of the crack width influence on the concrete pull-out load, similar as in the experiments, confirms that the concrete cone failure load decrease with the crack width increase. This decrease is relatively fast up to crack width $\Delta w=0.2 \mathrm{~mm}$ and reaching approximately $70 \%$ of the failure load for uncracked concrete. However, further increase of the crack width does not decrease failure load since reaching critical crack width 
(approx. $0.2 \mathrm{~mm}$ ) final load transfer mechanism is formed and further increase of crack width does not influence failure load. Three-dimensional numerical analysis of the headed anchor embedded in a cracked concrete indicate that the calculated relation between concrete cone failure load and crack width exhibit qualitatively and quantitatively good agreement with experimental observations.

6. Present numerical approach based on the nonlocal microplane model seems to be powerful tool in the analysis of the complicated 3D problems of the concrete structures. However, open question is the calibration of the material model and characteristic length of the nonlocal continuum $l_{c}$ which seems to be stressstrain dependant rather than in advanced fixed concrete property. Therefore, more promising results can be expected by the use of the new nonlocal concept that is based on the microcrack interaction approach. Indeed, first results obtained using this approach seems very promising (Ożbolt, 1992).

\section{References}

1. ACI 349-80 (1980) Code Requirements for Nuclear Safety Structures, Appendix B - Steel Embedments, American Concrete Institute, Detroit.

2. Ballarini, R.; Shah, S. and Keer, L. (1986) Failure Characteristics of Short Anchor Bolts Embedded in a Brittle Material, Proc. R. Soc. London, A 404, pp. 35-54.

3. Bažant, Z.P. (1984) Size effect in Blunt Fracture: Concrete, Rock, Metal. Journal of Engineering Mechanics, ASCE, 110(4), 518-535.

4. Bažant, Z.P., and Ożbolt, J., (1990) Nonlocal microplane model for fracture, damage, and size effect in structures. J. of Engrg. Mech., ASCE, 116(11), 2485-2504.

5. Bažant, Z.P., Ożbolt, J. and Eligehausen, R., (1992) Fracture Size Effect: I. Review of Evidence for Concrete Structures. Submitted to Journal of Str. Eng., ASCE.

6. Bażant, Z.P., Ożbolt, J. and Eligehausen, R., (1992) Fracture Size Effect: II. Should it go Into Concrete Design Code. Submitted to Journal of Str. Eng., ASCE.

7. Bažant, Z.P. (1992) New Nonlocal Damage Concept Based on Micromechanics of Crack Interactions, Report No. 92-t/C457n, Department of Civil Engineering, Northwestern University, USA.

8. Bode, H. and Hanenkamp, W., (1985) Zur Tragfahigkeit von Kopfbolzen bei Zugbeanspruchung. Bauingenier, 1985, 361-367. 
9. Cedolin, L. and Bażant, Z. P. (1980) Effect of Finite Element Choice in Blunt Crack Band Analysis. Comp. Meth. in Appl. Mec. and Eng., 24, 305-316.

10. Elfgren, L., Broms, C. E. and Johansson, H. (1980) Anchor Bolts in Reinforced Concrete Foundations, Report No. 1980:36, University Lulea, Sweden.

11. Eligehausen, R. and Sawade, G. (1985) Behavior of Concrete in Tension. Betonwerk + Fertigteil Technik, No. 5 and 6 .

12. Eligehausen, R., Fuchs, W. and Mayer, B. (1988). Loadbearing Behaviour of Anchor Fastenings in Tension. Betonwerk + Fertigteil Technik, 12/1987(1), $826-832$, and $1 / 1988(2), 29-35$.

13. Eligehausen, R. and Sawade. G. (1989) Analysis of Anchoring Behavior (Literature Review), Fracture Mechanics of Concrete Structures - RILEM Report, (ed L.Elfgren), Chapman and Hall, pp.263-280.

14. Eligehausen, R. and Sawade. G. (1989) A fracture mechanics based description of the pull-out behavior of head studs embedded in concrete, Fracture Mechanics of Concrete Structures - RILEM Report, (ed L. Elfgren), Chapman and Hall, pp. 263-280.

15. Eligehausen, R. and Ożbolt, J., (1990) Size effect in Concrete Structures, Application of Fracture Mechanics to Reinforced Concrete, (ed A. Carpinteri), Elsvier Applied Science, Torino, pp. 17-44.

16. Eligehausen, R., and Ożbolt, J., (1991) Use of the Tensile Strength in Anchorage to Concrete, Structural Concrete, IABSE Colloquium, IABSE-AIPCIVBH, Stuttgart.

17. Eligehausen, R., Bouška, P., Ćervenka, V. and Pukl, R. (1992) Size Effect of the Concrete Cone Failure Load of Anchor Bolts, FramCoS 1, (ed Bažant, Z.P.), Elsevier applied science, Breckenridge, USA, pp. 517-525.

18. Furche, J. (1988) Ausziehverzuche an Kiopfbolcen mit kleinen Unterkopfflachen und Flachen Hinterschnittwinkeln. Report No. 9/4-88/1, Institut ftr Werkstoffe im Bauwesen, Stuttgart University.

19. Krenchel, H. and Shah. S. (1985) Fracture Analysis of the Pull-Out Tests. Material and Structures, 18(108), 439-446.

20. Ottosen, N. S. (1981) Nonlinear Finite Element Analysis of Pull-Out Tests. Journal of Structural Division, 107(4) 591-603.

21. Ožbolt, J., and Eligehausen, R., (1990) Numerical Analysis of Headed Studs Embedded in Large Plain Concrete Blocks, Internal Report Nr. 4/10-90/9, Institut für Werkstoffe im Bauwesen, Stuttgart University, Germany. 
22. Ożbolt, J., (1991) The Edge Influence on the Pull-out Failure Load of the Headed Stud Anchors, Internal Report Nr. 4/12-91/11, Institut für Werkstoffe im Bauwesen, Stuttgart University. Germany.

23. Ožbolt, J., (1991) The Influence of the Crack Width on the Concrete Cone Failure Load, Internal Report Nr. 4/13-91/12, Institut für Werkstoffe im Bauwesen, Stuttgart University, Germany.

24. Ożbolt, J. and Bażant, Z.P., (1992) Microplane Model for Cyclic Triaxial Behavior of Concrete. Journal of Eng. Mech., ASCE, 118(7), 1365-1386.

25. Ožbolt, J., (1992) Smeard Crack Analysis - New Nonlocal Microcrack Interactions Approach, Internal Report Nr. 4/14-92/19, Institut für Werkstoffe im Bauwesen, Stuttgart University, Germany.

26. Rehm, G., and Martin, H. (1968). Zur Frage der Rissbegrencung im Stahlbetonbau. Beton - und Stahlbetonbau, (8), Berlin, 1-8.

27. Rehm, G., Eligehausen, R., and Mallie, R. (1988) Befestigungstechnik. Betonkalender 1988, 2, Wiehelm Ernst and Sohn, Berlin, Germany.

28. Sawade, G. (1992) A contribution to the behavior of concrete in tension. Thesis in the preparation, Stuttgart University. 